\title{
LEPROSY IN CYPRUS
}

On the invitation of the Director of Medical Services, I paid a short visit on September 21st, 1939, to the Island of Cyprus. The visit lasted only four days and I could not gain more than a general idea of the problem of leprosy in that time.

\section{The Amount and Types of Leprosy}

In Cyprus segregation of lepers is compulsory, and there are at present 122 casés segregated in the leper farm outside Nicosia. Of these nine were absent on leave, but I had an opportunity of examining 71 men and 42 women and classifying them according to the type of the disease and according to whether or not they were deformed and disabled as shown in the table :-

$$
\text { Type. }
$$

Advanced lepromatous

$\left(\mathrm{L}_{2}\right.$ and $\left.\mathrm{L}_{3}\right)$

Mild lepromatous

cases $\left(\mathrm{L}_{1}\right)$

With Tuberculoid

lesions $\left(\mathrm{N}_{\mathbf{1}}\right)$

With only residual

lesions

Without leprosy
Men. Women. Total.

$\begin{array}{lr}\text { Deformed } & \text { I5 } \\ \text { Undeformed } & \text { 2I } \\ \text { Deformed } & 7 \\ \text { Undeformed } & \text { I4 } \\ \text { Deformed } & \text { I } \\ \text { Undeformed } & - \\ \text { Deformed } & 9 \\ \text { Undeformed } & 3 \\ & \text { I }\end{array}$

I5

I6

3

I I5

I

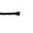

9

3

I
30

37

I0

I5

I

I3

5

I

The remarkable feature of these figures, when compared with similar statistics from institutions in Africa and India, is the great preponderance of lepromatous cases, that is of the severe open type associated with low resistance to the disease. There were only two cases of the neural resistant type with tuberculoid lesions. Taking only the active cases, the lepromatous type forms 98 per cent. of the whole; whereas in the African institutions it forms only 25 to 50 per cent., and in surveys made in India it is in a still smaller proportion. Only in the European patients in the Pretoria Leper Settlement in South Africa have I found a similar state of affairs; whereas the native population of the same institution gave only twenty-five per cent. of lepromatous cases. This would suggest at first sight that the lepromatous type preponderates among light coloured races, while the neural type is more common among dark coloured races. But this is not confirmed by findings elsewhere, as for instance in Malaya where the major tuberculoid type of lesion is more common among light-coloured Chinese than among darkcoloured Tamils. To what extent a systematic survey of leprosy throughout the island wouls reveal a higher proportinn of this 
latter form remains to be seen. I was informed of 40 casts formerly in the leper farm but now on parole, and presumably the most of these would have been of the neural type.

\section{DISTRIBUTION}

No attempt at a survey of leprosy has yet been attempted, and the only indication of the distribution of the disease is the towns and villages from which the patients have been admitted to the Leper Farm. I obtained information of 188 cases; of thesc: I2I are resident in the farm, I4 on parole and 53 dead. These arc distributed among $9 \mathrm{I}$ families as follows:-

$\begin{array}{ccc}\text { Number of present or jormer } & \text { Numbir of } & \\ \text { acknowied yed lepers in family. } & \text { jamilies. } & \text { Total cuses. } \\ \text { I } & 45 & 45 \\ 2 & 25 & 50 \\ 3 & 5 & 15 \\ 4 & 7 & 28 \\ 5 & 4 & 20 \\ 6 & 5 & 30\end{array}$

$\begin{array}{lll}\text { Total } & 9 \mathrm{I} & \mathrm{I} 88\end{array}$

Besides the 188 cases mentioned above, there are 26 other known cases on parole. These and the first mentioned I4 cases on parole report to the doctor once a month.

Another remarkable feature is that none of the cases come from the larger towns, confirming the usual finding that leprosy is a disease of the villages, and when found in towns it is chiefly by migration from villages. The $9 \mathrm{I}$ families mentioned above belong to 56 villages distributed all over the island. The region with most infected villages is round Paphos, and that with fewest infected villages is Tilliria to the north of the latter. Whether this comparative exemption from leprosy in Tilliria is due to the proximity of the copper mines is a matter for investigation.

The wide distribution of leprosy foci, and the fact that the great majority of cases are of the open, infectious type ( 67 being of the most dangerous $\mathrm{L}_{2}$ and $\mathrm{L}_{3}$ type), would suggest that there is ample opportunity for the spread of the disease, especially as in the villages there is considerable housing congestion and the people tend to be promiscuous in their habits. There are two other factors which would increase this danger. Most cases, though highly infectious, have not the nodular but the diffuse type of lepromatous lesions, which are not conspicuous and tend to escape detection till they are far advanced. Also most cases are in an advanced stage of infectiousness before they are admitted to the leper farm There- 
fore the present system of segregation does not get down to the root of the problem; it only removes a limited amount of the infection from contact with the population.

On the other hand, a fairly reliable index of the frequency of leprosy in a community is the number of deformed cases that are found, and I am told that there are comparatively few in the villages throughout the island.

\section{SUR VEY}

The above facts leave one in doubt as to the incidence of leprosy and the question as to whether or not it should be considered as a serious problem in the island. The only way to answer this question is by carrying out a careful survey.

This might be most effectively done by examination of contacts with known cases, and where necessary this might be supplemented by examination of school children. Compared with other public problems in the island, such as malaria, tuberculosis, malnutrition and trachoma, leprosy may be a minor one. It is one, however, which, if thoroughly investigated and dealt with for a few years, could be brought under effective control. I understand that leprosy in Cyprus is not regarded with horror to the extent that it is in other places. It is generally found that when a population becomes ' leprosy conscious' the disease tends to die out. Thus a survey should be accompanied by education of the people with regard to the nature of leprosy, its dangers and how they can be a voided. To carry out a thorough survey it would be necessary to employ an expert doctor for a number of years. I would suggest that the British Empire Leprosy Relief Association should, if possible, assist in the provision of such a doctor. Possibly the survey of other diseases might be included in his duties.

\section{ThE LePER FARM}

The present accommodation of the farm is only sufficient for Ioo patients. The admission of the present $\mathbf{2 2}$ cases has thus led to a certain amount of congestion, and some cases have had to be refused admission. If a survey were carried out there would presumably be need of considerably more accommodation.

The present staff consists of a part-time doctor, a matron, a lay superintendent, and a lay worker supplied by the British Empire Leprosy Relief Association to organise the social activities of the patients. There is also one female nurse and there are four guards. I consider that the efficiency of the treatment could be improved if the doctor were free to attend the farm at least three afternoons in the week. 
The compulsory system, which in the British Empire is in force in only a few places such as South Africa, Cyprus and Malta, has certain distinct disadvantages. When admitted to an institution against his will the patient tends to take up the attitude of nonco-operation. In effect he says: "you have brought me here against my will, it is up to you to do everything, I shall do nothing." This attitude is fatal in leprosy as regards the discipline of the institution and the chance of recovery of the patient. We have no "specific" for leprosy. The treatment consists of improving the physical and mental condition of the patient to the highest possible standard, and when this is attained the special treatment with chaulmoogra injections is of great value. On this account the nonco-operating patient with a grudge is not likely to benefit from treatment.

The present site of the farm is contrary to several of the generally accepted requirements. Among these requirements are: plenty of arable land and of water; not so near to a town or village that the patient will trespass there. The present site lacks both arable land and water and is far too near to Nicosia. Removal of the farm to a more suitable site has been contemplated for some time, and I consider that this should be done as soon as possible so that fresh accommodation may be prepared for new patients admitted as a result of the survey. This could be done at a minimum of expense by making the patients' houses with help of leper labour, and in the usual Cypriot style, only more sanitary.

The labour and the social life of the patients should be carefully regulated. In the most successful leper institutions a patients' committee is formed to maintain discipline and organise the social and other activities of the patients. With this in view the British Empire Leprosy Relief Association sent out a Toc $\mathrm{H}$ worker about a year ago. Unfortunately he has not yet so far succeeded in this aim. It takes some time to alter the prison spirit which a compulsory institution is apt to assume. On a new site, with abundant facilities for agriculture to which most of the patients are accustomed, and with the houses arranged in the form of a model village rather than as a barracks as at present, it should be possible to organise the farm on modern lines. In this way the sting would be taken from compulsion, the farm would attract patients, and the need for compulsion with all its evils would gradually disappear.

The patients are at present given a money ration of one shilling a day. I consider that able-bodied patients should earn a portion of their ration by their work. Also, in return for the service rendered them by the institution, they should do a certain amount of work for the community such as road repairs, growing of communal crops, etc. They should have land allotted to them for their farms, 
the produce of which they can eat themselves and sell the balance to the institution. Patients temporarily disabled from work should be removed to the institution hospital and actively treated till they are well. Specially prepared food should be supplied them in the hospital. Patients should be excused from work only on the doctor's certificate.

In addition to the exercise provided by work in the fields, there should be daily physical exercises for all who are fit. These should be carefully regulated so as to remove and prevent deformities and render the patients as physically fit as possible. These exercises should form a regular part of the treatment in the morning in the same way as the special treatment by injections, etc.

Many of the patients could be considerably improved by hospitalisation for the treatment of ulcers, and by operations for removal of bone. The treatment of eyes should be attended to; some are suffering from actual leprous infection of the eye, but a greater number from ectropion as the result of nerve leprosy, or from trachoma, entropion and trichiasis.

\section{Summary of Suggestions}

I. That the present leper farm be replaced by a new settlement on a suitable site.

2. That the present compulsory system be modified by making the settlement more attractive, and encouraging the patients to co-operate.

3. Improvements in treatment would also make the institution more attractive by hastening the recovery of patients.

4. A survey combined with an educational campaign should be carried out.

5. The necessary modification of staff should be made so that these measures are possible. 